\title{
Geographical variation of presentation at diagnosis of Type I diabetes in children: the EURODIAB Study
}

\author{
C. Lévy-Marchal ${ }^{1}$, C.C.Patterson ${ }^{2}$, A. Green ${ }^{3}$ on behalf of the EURODIAB ACE Study Group* \\ ${ }^{1}$ INSERM U457, Robert Debré Hospital, Paris, France \\ ${ }^{2}$ Department of Epidemiology and Public Health, The Queen's University of Belfast, Belfast, UK \\ ${ }^{3}$ Department of Epidemiology and Social Medicine, University of Åarhus, Denmark
}

\section{Abstract}

Aims/hypothesis. We aimed to describe the frequency and degree of diabetic ketoacidosis in children across Europe at the time of diagnosis of Type I (insulin-dependent) diabetes mellitus and to determine if factors such as age and geographical region contribute to the risk of diabetic ketoacidosis.

Methods. The study was part of the EURODIAB project. A total of 24 centres, covering a population at risk of more than 15 million children below 15 years of age, recruited 1260 children at the time of clinical diagnosis.

Results. Polyuria, by far the most frequent symptom, was observed in $96 \%$ of the children. In only $25 \%$ of the children was the duration of symptoms less than 2 weeks and this proportion was larger in the under 5 year age-group ( 37 vs $22 \% ; p<0.001$ ). Of the 11 centres that recorded diabetic ketoacidosis status, the overall proportion with diabetic ketoacidosis
$(\mathrm{pH}<7.3)$ was $40 \%(95 \%-\mathrm{CI}: 36-44 \%)$ in at least $90 \%$ of cases. After stratification by centre, the odds ratio for diabetic ketoacidosis in the under 5 agegroup was $1.02(95 \%-\mathrm{CI}: 0.69-1.49)$ relative to the older children. There was significant variation between the 11 centres in the frequency of diabetic ketoacidosis which ranged from 26 to $67 \%$ $(p=0.002)$. An inverse correlation between the frequency of diabetic ketoacidosis and the background incidence rate was found in these centres (Spearman's rank correlation, $r_{\mathrm{s}}=-0.715 ; p=0.012$ ).

Conclusion/interpretation. Rising standards of medical information and greater awareness concurrent with an overall increase in incidence could have resulted in changes in the clinical presentation at onset of Type I childhood diabetes in Europe. [Diabetologia (2001) 44 [Suppl 3]: B 75-B 80]

Keywords Type I diabetes, incidence, presentation, ketoacidosis, childhood, $\mathrm{pH}$.
Type I (insulin-dependent) diabetes mellitus in childhood results from the chronic autoimmune destruction of the pancreatic beta cells and leads to a pronounced reduction in capacity for insulin secretion at the time of clinical manifestation [1]. The clinical onset of the disease is acute in most cases. Diabetic ketoacidosis (DKA) is commonly found at onset although the frequency varies threefold over time in different settings. A valid comparison is difficult to

Corresponding author: Claire Lévy-Marchal, MD, INSERM U457-Hôpital Robert Debré, 75019 Paris, France

Abbreviations: DKA, Diabetic ketoacidosis.

* see Acknowledgements make because there is no standardized definition for DKA [2-7]. Clinical presentation has been said to have changed over the 1980 s to a less severe picture $[8,9]$. However, DKA is an important cause of death and morbidity in children, mostly due to cerebral oedema in the course of resuscitation [9-11].

Incidence of the disease in children varies widely across Europe [12]. Several reports from registries included in the EURODIAB network suggest that incidence rates in children have been rising for the last two decades [13-25]. There is no indication so far that the different levels of risk are associated with different patterns of clinical presentation at onset. It is still not known if the risk of disease in the background population is associated with the severity of it at pre- 
Table 1. Characteristics of the EURODIAB study centres

\begin{tabular}{|c|c|c|c|c|c|c|}
\hline Centre & Geographical area & $\begin{array}{l}\text { Population } \\
\text { at risk }\end{array}$ & $\begin{array}{l}\text { Incidence rate } \\
\text { per } 100000 \\
\text { from } 1989-1995\end{array}$ & $\begin{array}{l}\text { Estimate of com- } \\
\text { pleteness of as- } \\
\text { certainment }(\%)\end{array}$ & $\begin{array}{l}\text { Total patients } \\
\text { registered in } \\
\text { year of study }\end{array}$ & $\begin{array}{l}\text { Number of pa- } \\
\text { tients recruited } \\
\text { for the study }\end{array}$ \\
\hline A1 & Austria & 1382514 & 9.4 & 100 & 158 & 140 \\
\hline E1 & Iceland & 64589 & 13.9 & 100 & 10 & 10 \\
\hline $\mathrm{F} 1$ & France (four regions) & 1647218 & 8.9 & 99 & 149 & 139 \\
\hline H1 & The Netherlands (five regions) & 554474 & 12.5 & 96 & 61 & 53 \\
\hline I4 & Italy (Eastern Sicily) & 220551 & 11.6 & 98 & 23 & 23 \\
\hline $\mathrm{J} 1$ & Israel & 1502079 & 5.86 & 71 & 70 & \\
\hline K1 & Lithuania & 816636 & 7.6 & 100 & 62 & 58 \\
\hline $\mathrm{K} 2$ & Latvia & 538560 & 7.1 & 100 & 28 & 28 \\
\hline K3 & Estonia & 314018 & 11.1 & 100 & 38 & 39 \\
\hline L1 & Luxembourg & 71746 & 11.9 & 100 & 11 & 9 \\
\hline $\mathrm{U} 1$ & United Kingdom (Northern Ireland) & 391258 & 22.2 & 99 & 77 & 77 \\
\hline $\mathrm{U} 3$ & United Kingdom (Leicestershire) & 181762 & 17.1 & 98 & 31 & 28 \\
\hline W1 & Poland (eight regions) & 1297378 & 7.0 & 100 & 94 & 59 \\
\hline W2 & Poland (three cities) & 786364 & 6.6 & 100 & 17 & 17 \\
\hline Y1 & Slovenia & 373793 & 8.5 & 100 & 21 & 21 \\
\hline $\mathrm{Z} 1$ & Slovak republic & 1238470 & 9.2 & 100 & 120 & 109 \\
\hline
\end{tabular}

Incidence rates are calculated per 100000 children below the age of 15 years and per year

${ }^{\text {a }}$ Data is for whole countries unless stated otherwise

sentation. With the exception of some reports identifying a young age at onset, risk factors for DKA are not known [1, 10, 26, 27].

The EURODIAB network is an epidemiological resource which was established in 1989 with the aim of characterizing more comprehensively the epidemiology and determinants of childhood Type I diabetes across Europe. The first phase aimed to confirm the wide variation in incidence rates across Europe using prospective registration of new cases according to uniform methodology. The highest rates were recorded in Finland, Norway and Denmark, and the lowest in Greece and Romania [28].

This study, part of the EURODIAB project, aimed to describe the severity of the disease at onset throughout Europe based on the frequency and the degree of DKA at the time of diagnosis and to determine if factors such as age and incidence contributed to the risk of DKA.

\section{Methods and materials}

Study centres. Altogether 24 EURODIAB centres participated in this study (Table 1) covering a population at risk of over 15 million children under 15 years of age.

Definition of the cases. All children included in the survey were part of the basic incidence surveillance cohort gathered through a prospective and uniform protocol described previously in detail [28]. To maintain the high degree of complete- ness observed in the previous EURODIAB reports, the study centres aimed to recruit at least $80 \%$ of the cases included in the basic incidence surveillance to fulfill the study eligibility criteria. All but 2 of the 24 local study centres met these criteria. Consecutive cases over one full calendar year were examined by each centre, the starting date varying from centre to centre between 1 January 1989 and 1 January 1994.

Validation of ascertainment. The incidence surveillance protocol required that each centre use two independent sources of case identification. Completeness of ascertainment was estimated using the capture-recapture method [29]. The degree of completeness is given for each centre for the study period in Table 1.

Data collection. Data was collected using a standardized questionnaire specifically developed for the study during workshops with representatives of the study centres.

Clinical and biological data was based on characteristics recorded routinely at the time of diagnosis and obtained from the hospital or medical records. The local investigators filled in the questionnaires following the common guidelines supplied to all centres. Questionnaire data was reviewed, entered and analysed at the coordinating centre (INSERM U457, Paris, France).

Characteristics covered the clinical and biological pictures at the time of the first insulin treatment.

The clinical symptoms at entry were determined using a list agreed by the coordinating study group for which the type of symptoms that precipitated the visit to the doctor were assessed with a "yes/no" tick.

The duration of symptoms, the level of consciousness at the first medical examination (classified into three categories of normal, altered consciousness and coma) and the weight loss, expressed as a percentage of body weight, were also assessed. 
Table 2. Symptoms before diagnosis among 1260 children with Type I diabetes

\begin{tabular}{lcl}
\hline & $\begin{array}{l}\text { Symptom noted } \\
n(\%)\end{array}$ & $\begin{array}{l}\text { First symptom } \\
n(\%)\end{array}$ \\
\hline Polyuria & $1159(96)$ & $854(71)$ \\
Weight loss & $731(61)$ & $104(9)$ \\
Fatigue & $630(52)$ & $82(7)$ \\
Abdominal pain & $277(23)$ & $31(3)$ \\
Changes in consciousness & $137(11)$ & $22(2)$ \\
Others & $238(19)$ & $36(3)$ \\
No symptom/unspecified & $16(1)$ & $78(6)$ \\
No information & 53 & 53 \\
\hline
\end{tabular}

Table 3. Characteristics at the time of diagnosis of Type I diabetes in children below 15 years of age

\begin{tabular}{llc}
\hline Biological characteristic & $n$ & Median $\left(10^{\text {th }}-90^{\text {th }}\right.$ centiles $)$ \\
\hline Plasma glucose & 1260 & $21.8(13.0-37.7)$ \\
pH & 1037 & $7.33(7.12-7.42)$ \\
Osmolarity $^{\text {a }}$ & 1128 & $430.2(411.5-451.6)$ \\
Ketonuria $^{2}$ & 1199 & $970(81 \%)$ \\
\hline
\end{tabular}

${ }^{a}$ Osmolarity was assessed as the sum of plasma glucose $+2 \mathrm{xNa}$

The biological characteristics measured at entry were the plasma glucose, ketonuria assessed by urine strips, $\mathrm{pH}, \mathrm{Na}$, urea.

As for definitions, osmolarity was calculated as plasma glucose $+2 \cdot \mathrm{Na}$.

Classification of DKA was based on the $\mathrm{pH}$ value, with mild DKA defined as $\mathrm{pH}<7.3$ and severe DKA as $\mathrm{pH}<7.1$.

Statistical analyses. All comparisons were stratified by the centre using either the Mantel-Haenszel method for categorical variables or multiple regression incorporating centre effects for quantitative variables.

The association between DKA and the background incidence was assessed using Spearman's rank correlation coefficient.

Data was analysed using the SPSS and SAS statistical software packages. A $p$ value of less than 0.05 was considered to be statistically significant.

\section{Results}

Subjects. In total, 1260 children below 15 years of age at the time of diagnosis were recruited into the study by the 24 centres. Recruitment rates and characteristics of the centres are given in Table 1 . Children included in the study represented $91 \%$ of the total number of children included in the incidence surveillance study over the same calendar period.

Presentation at diagnosis. Clinical symptoms at the time of diagnosis are given in Table 2. Polyuria was by far the most frequent symptom observed in $96 \%$ of the children at the time of clinical diagnosis. Abdominal pain was seen in $23 \%$ of the children.
Table 4. Description of the patients diagnosed with severe DKA $(\mathrm{pH}<7.1 ; n=100)$

\begin{tabular}{ll}
\hline Clinical characteristic $^{\mathrm{a}}$ & \\
\hline Age (year) means $\pm \mathrm{SD}$ & $8.25 \pm 4.17$ \\
Duration of symptoms $<2$ weeks & $25 \%$ \\
Delay before diagnosis $\leq 1$ day & $76 \%$ \\
Delay before treatment < 1 day & $95 \%$ \\
Weight loss (\% body weight) means $\pm \mathrm{SD}$ & $-5.02 \pm 5.44$ \\
Altered consciousness or coma & $60 \%$ \\
Coma & $16 \%$ \\
Plasma glucose (mmol/l) means $\pm \mathrm{SD}$ & $29.78 \pm 11.40$ \\
Ketonuria & $89 \%$ \\
Osmolarity (mmol/l) means $\pm \mathrm{SD}$ & $437 \pm 30$ \\
Hospitalization & $89 \%$ \\
IV treatment & $87 \%$ \\
\hline
\end{tabular}

a means \pm SD are indicated unless otherwise stated

The most frequent cluster of symptoms at diagnosis was polyuria, fatigue and weight loss. The most common first symptoms to be noticed by the family were polyuria $(71 \%)$, weight loss $(9 \%)$ and fatigue $(7 \%)$.

In only $25 \%$ of the children was the duration of symptoms shorter than 2 weeks and this proportion was larger in the younger children $(37 \%$ in 0 to 4 year-old age group vs $22 \%$ in older age groups; Mantel Haenszel $\left.\chi^{2}=21.4, d f=1 ; p<0.001\right)$. In $76 \%$ of the children the delay between the first visit and diagnosis was less than 2 days, with no statistical difference evident between age groups (Mantel Haenszel $\left.\chi^{2}=0.00, d f=1 ; p=0.96\right)$. A simultaneous febrile illness was noted in $20 \%$ of the cases and was more frequently observed in the young $(25 \%$ in 0 to 4 year-old age group vs $18 \%$ in older age groups; Mantel Haenszel $\chi^{2}=7.30, d f=1 ; p=0.007$ ).

Altogether, 23 children ( $2 \%$ ) were in coma and a further $14 \%$ presented with altered consciousness at the time of diagnosis. As many as $89 \%$ of the children were admitted to hospital for initial treatment and this treatment was initiated on the day of diagnosis in $91 \%$ of the cases.

Diabetic ketoacidosis. Biological characteristics measured at diagnosis are indicated in Table 3.

Overall $82 \%$ of the patients had $\mathrm{pH}$ data recorded and the proportion of DKA $(\mathrm{pH}<7.3)$ among these patients was $42 \%(95 \%-\mathrm{CI}: 39-46 \%)$. When DKA was further subdivided into mild DKA $(7.1<$ $\mathrm{pH}<7.3)$ and severe DKA $(\mathrm{pH}<7.1)$, the proportions were 33 and $9 \%$, respectively. In at least $90 \%$ of the patients a slightly lower figure of $40 \% \quad(95 \%$ CI:36-44\%) was obtained when the frequency of DKA $(\mathrm{pH}<7.3)$ was calculated in the 11 centres that recorded DKA status.

The data of patients with severe DKA is given in Table 4. Comparisons of the characteristics of patients with DKA $(\mathrm{pH}<7.3)$ and those without are shown in Table 5. 
Table 5. Comparisons of the presentation at diagnosis between children with or without DKA $(\mathrm{pH}<7.3)$

\begin{tabular}{|c|c|c|c|}
\hline Clinical characteristics $^{\mathrm{a}}$ & No DKA $(n=595)$ & DKA $(n=440)$ & $p$ value $^{\mathrm{b}}$ \\
\hline Age (year) means \pm SD & $8.67 \pm 3.78$ & $8.34 \pm 4.00$ & 0.18 \\
\hline Duration of symptoms < 2 week $(\%)$ & 24.2 & 24.8 & 0.80 \\
\hline Delay before diagnosis $\leq 1$ day $(\%)$ & 76.9 & 76.7 & 0.63 \\
\hline Weight loss ( $\%$ body weight $)$ means \pm SD & $3.32 \pm 3.53$ & $4.84 \pm 3.87$ & $<0.001$ \\
\hline Altered consciousness or coma $(\%)$ & 7.6 & 31.4 & $<0.001$ \\
\hline Coma $(\%)$ & 0.7 & 4.7 & $<0.001$ \\
\hline Osmolarity $(\mathrm{mmol} / \mathrm{l})$ means $\pm \mathrm{SD}$ & $431 \pm 16$ & $432 \pm 24$ & 0.16 \\
\hline Hospitalization $(\%)$ & 92.0 & 89.5 & 0.41 \\
\hline IV treatment (\%) & 46.6 & 77.1 & $<0.001$ \\
\hline
\end{tabular}

${ }^{\mathrm{a}}$ means $\pm \mathrm{SD}$ are indicated unless stated otherwise

b All comparisons are stratified by centre

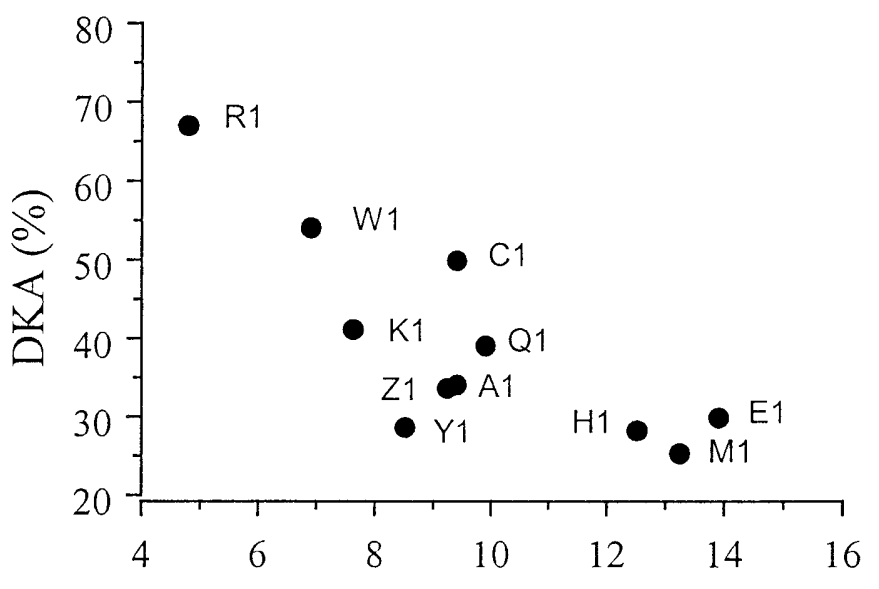

Incidence rate (per 100000 person-years)

Fig. 1. Correlation between the proportion of DKA at diagnosis and the background incidence rates for 11 centres where DKA data collection was $90 \%$ complete. For key see Table 1

The proportion of patients with DKA ranged from 11 to $67 \%$ across centres. The proportion of patients with DKA varied between the 11 centres which had the most complete data, from 26 to $67 \%$ $(p=0.002)$. There was a inverse correlation between the proportion of DKA and the background Type I incidence rate for these centres $\left(r_{\mathrm{s}}=-0.715\right.$; $p=0.012)$ (Fig. 1).

There was no evidence of differences in DKA frequency according to gender (data not shown). After stratification across 11 centres, the Mantel Haenszel estimate of the odds on DKA for the under-5 agegroup relative to the rest was $1.02(95 \% \mathrm{CI}=$ 0.69-1.49).

\section{Discussion}

The EURODIAB network has confirmed large variations in the incidence rates of Type I diabetes in chil- dren across Europe [28]. The same network has also established age-group differences in incidence rate by geographical region [4]. This study shows that no differences in the proportion of children presenting with ketoacidosis could be observed between age groups but that differences existed between geographical regions with higher rates of diabetic ketoacidosis found in regions with lower incidence rates. The proportion of children with DKA at diagnosis was $40 \%$ of the whole study population. When the calculation was restricted to the centres where completeness of data was $90 \%$ or more, this proportion rose to $42 \%$. The large variation in the rate of DKA at diagnosis is in keeping with results previously published in different countries $[2,3,5-7,30]$. Although this study was based on a uniform and prospective protocol and on a population base larger than in any previous survey, we found only a slightly lower range of variation for DKA across the centres compared with previously published literature. Given that the rate of DKA did not change much for complete or incomplete data, it is not likely that the completeness of data explains the large variability in the proportion of DKA across centres.

Death was not registered in this study. It is plausible that the children who die at onset of the disease have ketoacidosis, in which case the proportion of patients with DKA has been underestimated in our study. It is also probable that deaths are more common in poorer countries. Therefore the magnitude of variation in the proportion of children with DKA could actually be larger than the one we have reported but it is not likely that the small number of deaths missing from our series could introduce much bias in our conclusions.

Collection of data was based on a prospective protocol and information routinely recorded during the initial care of the diabetic children. Children were therefore observed at different times of the day. This could partly explain why $7.6 \%$ of the children with no biological DKA were reported to have had chan- 
ges in consciousness. It is also well known that clinical condition can fluctuate very rapidly in children.

An inverse relation was found between incidence rates and proportions of children with DKA. This analysis was restricted to the centres where completeness of data was $90 \%$ or more. This $90 \%$ figure was chosen arbitrarly as a compromise to minimize a possible bias while retaining a larger number of centres in the analysis. Primary care organization and the care of diabetic children does vary across countries. The frequency of DKA might be lower in countries with a more prosperous lifestyle and with a more organized and efficient health care system. The most recent data produced by our network suggest that indicators of wealth are strongly associated with incidence rates across Europe [31, 32]. The inverse relation between incidence rates and proportions of children with ketoacidosis is consistent with a high level of medical awareness which increases the chances of early diagnosis and consequently reduces the risk of ketoacidosis. Our observation supports the hypothesis that the proportion of DKA is partly, and inversely, related to health-care standards.

The clinical presentation at diagnosis of Type I is more sudden and severe in children under 5 years of age $[2,5-7,27,33]$. In contrast with previous studies from single centres, our data does not show a sharp increase in the risk of DKA in the young. This probably cannot be explained by a drastic change in the overall picture of presentation at onset because the average proportion of DKA is $42 \%$ in our study. A minimal delay was observed in the initiation of treatment, and the interval between the first visit and initial treatment was not affected by age. These observations suggest that the medical awareness of childhood Type I diabetes has increased in Europe leading to more rapid and efficient initial care.

Our data shows the geographical variation in the risk of DKA at the onset of Type I diabetes in children. Our results also point towards increased medical awareness in Europe so that the risk of DKA in the most sensitive patients, such as very young children, is reduced even though DKA at diagnosis remains common. Standards of medical information and greater awareness, which have been rising parallel with incidence, could have induced changes in the clinical presentation at onset of Type I childhood diabetes in Europe.

\section{The EURODIAB ACE Study Group*}

A1, Austria: E. Schober, Department of Paediatrics, University of Vienna, Vienna. C1, Hungary: G. Soltesz, Department of Paediatrics, University Medical School, Pécs. E1, Iceland: A. V. Thorsson, Department of Paediatrics, Reykjavik Hospital, Reykjavik. F1, France: C. Lévy-Marchal, INSERM U457, Ro- bert Debré Hospital, Paris. H1, The Netherlands: M. Reeser, Juliana Children's Hospital, Gravenhage. I2, Italy (Lazio): P. Pozzilli, Biomedical University Campus, Rome. I3, Italy (Sardinia): M. Songini, Department of Internal Medicine, Cagliari. I4, Italy (Eastern Sicily): F. Purrello, Department of Endocrinology, Garibaldi Hospital, Catania. J1, Israel: Z. Laron-Marsh, Department of Endocrinology and Diabetes, Ramat Efal. K1, Lithuania: B. Urbonaité, Laboratory of Paediatric Endocrinology, Kaunas Medical Academy, Kaunas. K2, Latvia: G. Brigis, Public Health and Epidemiology, Latvian Academy of Medicine, Riga. K3, Estonia: T. Podar, Hospital of Endocrinology, Tartu. L1, Luxembourg: C. de Beaufort, Luxembourg Paediatric Clinic, Luxembourg. M1, Germany (Düsseldorf region): G. Giani, Biometry and Epidemiology, Diabetes Research Institute, Düsseldorf. P1, Portugal (Madeira island): S. Abreu, Department of Endocrinology, Funchal Hospital Centre. P3, Portugal (Algarve region): E. A. Pina, Department of Medicine, Faro District Hospital, Faro. Q1, Bulgaria (western part): V. Christov, Clinic of Endocrinology, University Alexandrov Hospital, Sofia. R1, Romania: C. Ionescu-Trigoviste, Institute of Diabetes "N. Paùlescù, Hospital "Dr. Cantacuzino", Bucharest. U1, United Kingdom (Northern Ireland): D. Carson, Department of Child Health, Queen's University Belfast, Belfast. U3, United Kingdom (Leicestershire): N. Raymond, Epidemiology and Public Health, University of Leicester, Leicester. W1, Poland (eight western provincies): D. Wozncka, Paediatric Endocrinology and Diabetes, University of Medical Sciences in Poznan, Poznan. W2, Poland (three cities): P. Jarozs-Jobot, Department of Paediatric Endocrinology, Silesia School of Medicine, Katowice. Y1, Slovenia: C. Krzisnik, Endocrinology, Diabetes and Metabolic Diseases, University Medical Center of Ljubljana, Ljubljana. Z1, Slovak Republic: D. Michalkova, First Paediatric Clinic, University Komensky, Bratislava.

Acknowledgements. This study was part of the EURODIAB ACE project supported by a European Community Concerted Action Programme (Grants BMH1-CT92-0043 and BMH4CT96-0577). We thank Dr E. Domingues-Muriel for her expert assistance in the coordination of the study and G. Brutti for her excellent secretarial assistance in the management of the EURODIAB network.

\section{References}

1. Komulainen J, Lounamaa R, Knip M, Kaprio E A, Akerblom H K (1996) Ketoacidosis at the diagnosis of Type 1 (insulin dependent) diabetes mellitus is related to poor residual beta cell function. Childhood Diabetes in Finland Study Group. Arch Dis Child 75: 410-15

2. Karjalainen J K, Samela P, Ilonen J, Surrcel H M, Knip M (1989) A comparison of childhood and adult Type 1 diabetes mellitus. N Engl J Med 320: 881-86 
3. Daneman D, Knip M, Kaar M L, Sochett E (1990) Comparison of children with Type 1 (insulin-dependent) diabetes in northern Finland and southern Ontario: differences at disease onset. Diabetes Res 14: 123-26

4. Lévy-Marchal C, Patterson C, Green A, the EURODIAB ACE Study Group (1995) Variation by age group and seasonality at diagnosis of childhood IDDM in Europe. Diabetologia 38: 823-30

5. Pinkney J H, Bingley P J, Sawtell P A, Dunger D B, Gale E A (1994) Presentation and progress of childhood diabetes mellitus: a prospective population-based study. The Bart'sOxford Study Group. Diabetologia 37: 70-4

6. Sebastiani L, Visalli N, Adorisio E et al. (1996) A 5-year (1989-1993) prospective study of the incidence of IDDM in Rome and the Lazio region in the age-group 0-14 years. Diabetes Care 19: 70-3

7. Savova R, Popova G, Koprivarova K et al. (1996) Clinical and laboratory characteristics of Type 1 (insulin dependent) diabetes mellitus at presentation among Bulgarian children. Diabetes Res Clin Pract 34 [Suppl 1]: S159-63

8. Pozzilli P, Andreani D (1990) Type 1 diabetes at presentation: the scene changes. Diabet Med 7: 762-63

9. Japan, Poland, the-Netherlands, Pittsburgh Diabetes Research Groups (1990) How frequently do children die at the onset of insulin-dependent diabetes ? Analyses of registry data from Japan, Poland, the Netherlands and Allegheny County. Diabetes Nutr Metab 3: 57-62

10. Kostraba J N, Dorman J S, LaPorte R E et al. (1991) The investigation of age at onset as a risk factor for mortality in persons with insulin-dependent diabetes mellitus using Cox proportional hazards models. Am J Epidemiol 133: 67-72

11. Rosenbloom A L (1990) Intracerebral crises during treatment of diabetic ketoacidosis. Diabetes Care 13: 22-33

12. The EURODIAB ACE Study Group (2000) Variation and trends in incidence of childhood diabetes in Europe. Lancet 355: 873-76

13. Dahlquist G, Mustonen L, the Swedish Childhood Diabetes Study Group (2000) Analysis of 20 years of prospective registration of childhood onset diabetes- time trends and birth cohort effects. Acta Paediatr 89: 1231-37

14. Feltbower RG, McKinney PA, Bodansky HJ (2000) Rising incidence of childhood diabetes is seen at all ages and in urban and rural settings in Yorkshire, United Kingdom. Diabetologia 43: 682-84

15. Gardner S G, Bingley P J, Sawtell P A, Weeks S, Gale E A (1997) Rising incidence of insulin dependent diabetes in children aged under 5 years in the Oxford region: time trend analysis. The Bart's-Oxford Study Group. BMJ 315: 713-17

16. Green A, Andersen P K, Svendsen A J, Mortensen K (1992) Increasing incidence of early onset Type 1 (insulindependent) diabetes mellitus: a study of Danish male birth cohorts. Diabetologia 35: 178-82

17. Lévy-Marchal C (1998) Evolution de l'incidence du diabète insulino-dépendant de l'enfant en France. Rev Epidemol Sante Publique 46: 157-63
18. Onkamo P, Vaananen S, Karvonen M, Tuomilehto J (1999) Worldwide increase in incidence of Type I diabetes - the analysis of the data on published incidence trends. Diabetologia 42: 1395-1403

19. Padaiga Z, Tuomilehto J, Karvonen M et al. (1997) Incidence trends in childhood onset IDDM in four countries around the Baltic sea during 1983-1992. Diabetologia 40: 187-192

20. Rosenbauer J, Herzig P, von Kries R, Neu A, Giani G (1999) Temporal, seasonal, and geographical incidence patterns of type I diabetes mellitus in children under 5 years of age in Germany. Diabetologia 42: 1055-59

21. Ruwaard D, Hirasing R A, Reeser M H et al. (1994) Increasing incidence of type 1 diabetes in the Netherlands. Diabetes Care 17: 599-601

22. Schober E, Schneider U, Waldhör T, Tuomilehto J, the Austrian Diabetes Incidence Study Group (1995) Increasing incidence of IDDM in Austrian children. Diabetes Care 18: $1280-83$

23. Soltesz G, Madacsy L, Bekefi D, Dankoo I, the Hungarian Childhood Diabetes Study Group (1990) Rising incidence of Type 1 diabetes in Hungarian children. Diabet Med 7: 111-14

24. Tuomilehto J, Karvonen M, Pitkaniemi J et al. (1999) record-high incidence of Type I (insulin-dependent) diabetes mellitus in Finnish children. The Finnish Childhood Type I Diabetes Registry Group. Diabetologia 42: 655-60

25. Tzaneva V, Iotova V, Bruining G J (1998) Increase in IDDM incidence in Bulgarian children (1974-1995). J Pediatr Endocrinol Metabol 11: 725-32

26. Jefferson I G, Smith M A, Baum J D (1985) Insulin dependent diabetes in under 5 year olds. Arch Dis Child 60: 1144-48

27. Ludvigsson J, Heding L G (1978) Beta-cell function in children with diabetes. Diabetes 27 [Suppl 1]: 230-34

28. Green A, Gale EAM, Patterson CC, the Eurodiab ACE Study Group (1992) Incidence of childhood-onset insulindependent diabetes mellitus: the EURODIAB ACE Study. Lancet 339: 905-09

29. Hook E B, Regal R R (1992) The value of capture-recapture methods even for apparent exhaustive surveys. Am J Epidemiol 135: 1060-67

30. Lévy-Marchal C, Papoz L, de Beaufort C et al. (1992) Clinical and laboratory features of Type 1 diabetic children at the time of diagnosis. Diabet Medic 9: 279-83

31. EURODIAB ACE Study Group (2001) Geographical variation in European incidence of childhood onset diabetes. A wealth-related disease? Diabetologia [Suppl 3]: B 9B 16

32. Cherubini V, Carle F, Gesuita R et al. (1999) Large incidence variation of Type I diabetes in central-southern Italy 1990-1995: lower risk in rural areas. Diabetologia 42: 789-92

33. Komulainen J, Kulmala P, Savola K et al. (1999) Clinical, autoimmune, and genetic characteristics of very young children with type I diabetes. Childhood Diabetes in Finland (DiMe) Study Group. Diabetes Care 22: 1950-55 